\title{
Fossil population structure and mortality analysis of the cave bears from Urşilor Cave, north-western Romania
}

\author{
Marius Robu \\ Acta Palaeontologica Polonica 61 (2), 2016: 469-476 doi:http://dx.doi.org/10.4202/app.00201.2015
}

Research in cave bear palaeobiology focusing on population structure and mortality analysis may improve our understanding regarding the ecology of this species which vanished at the end of Marine Isotope Stage (MIS) 3, prior to Last Glacial Maximum (LGM), if assessed populations are large enough. Such population is available in Urşilor Cave, from north-western Romania, known as one of the most rich and complex European MIS3 cave bear sites. From the palaeontological excavation, situated at the lower level of the cave (= Scientific Reserve), more than 210 cave bear isolated lower molars, 160 mandibles and almost 180 canines were extracted and analyzed. The results obtained on the wear stages of the studied molars and mandibles indicated an "L"-shaped curve and suggest a non-attritional death pattern and a bone assemblage juvenile dominated. Moreover, the sex-ratio of upper and lower canines indicates a net dominance of females (5.4 females: 1 male). Although a "catastrophic" death pattern was obtained for cave bears, the animals seem to have died diachronically (non-simultaneously), over a time span of more than 6000 years. The triangular graph of age distribution is not appropriate for death assemblages from traps such as karst caves, where taphonomic processes like predation or scavenging would have played a less important role.

Key words: Mammalia, Ursus spelaeus, cave taphonomy, death pattern, sex-ratio, Romanian Carpathians, Urşilor Cave.

Marius Robu [marius.robu@ iser.ro], "Emil Racoviţă” Institute of Speleology, Romanian Academy, Calea 13 Septembrie, 13, 050711, Bucharest, Romania.

This is an open-access article distributed under the terms of the Creative Commons Attribution License (for details please see creativecommons.org), which permits unrestricted use, distribution, and reproduction in any medium, provided the original author and source are credited. 
For Full text $(612.0 \mathrm{kB})$ ।

For 5 Supplementary file $(137.7 \mathrm{kB})$ 